\title{
Evaluation of the PV Cell Operation Temperature in the Process of Fast Switching to Open-Circuit Mode
}

\author{
Valery D. Rumyantsev, Nikolay Yu Davidyuk, Alexander V. Chekalin, Dmitry A. Malevskiy, Alexander N. Pan'chak, \\ Nikolay A. Sadchikov, Viacheslav M. Andreev, and Antonio L. Luque
}

\begin{abstract}
A procedure for measuring the overheating temperature $(\Delta T)$ of a p-n junction area in the structure of photovoltaic (PV) cells converting laser or solar radiations relative to the ambient temperature has been proposed for the conditions of connecting to an electric load. The basis of the procedure is the measurement of the open-circuit voltage $\left(V_{\mathrm{OC}}\right)$ during the initial time period after the fast disconnection of the external resistive load. The simultaneous temperature control on an external heated part of a PV module gives the means for determining the value of $V_{O C}$ at ambient temperature. Comparing it with that measured after switching OFF the load makes the calculation of $\Delta T$ possible. Calibration data on the $V_{\mathrm{OC}}=f(T)$ dependences for single-junction AlGaAs/GaAs and triple-junction InGaP/GaAs/Ge PV cells are presented. The temperature dynamics in the PV cells has been determined under flash illumination and during fast commutation of the load. Temperature measurements were taken in two cases: converting continuous laser power by single-junction cells and converting solar power by triple-junction cells operating in the concentrator modules.
\end{abstract}

Index Terms-Energy dissipation, photovoltaic (PV) cells, temperature measurement.

\section{INTRODUCTION}

$\mathbf{E}$ FFICIENCIES of $55-60 \%$ and $42-46 \%$ have been achieved in the conversion of intense laser and concentrated solar radiations, respectively [1]-[8]. This was achieved by means of the modules with single-junction or multijunction photovoltaic (PV) cells based on III-V materials. Note that just the concept of converting high-intensive radiation allows the possibility of achieving highest efficiency. This logarithmical rise in output voltage is accompanied by a proportional increase in photocurrent. As these PV cells operate at a high optical power and at photocurrent densities of the order of $10 \mathrm{~A} / \mathrm{cm}^{2}$ and higher, the cell temperatures may be in the range of 60 $70^{\circ} \mathrm{C}$ [9]. Removal of residual heat is one of the key problems in optimizing PV modules. The main parameter characterizing the effectiveness of the heat removal from a PV cell is the p$n$ junction overheating temperature $\Delta T$ (or that of an area of closely located p-n junctions in a multijunction PV cell) with reference to the ambient temperature. In practice, the estimation of PV cell temperature in the measurement of the open-circuit $(\mathrm{OC})$ voltage $\left(V_{\mathrm{OC}}\right)$ is the most used [10], [11]. Note that in the operational mode, a substantial part of the incoming power (of the order of approximately $40 \%$ ) is dissipated not in a PV cell but in an external electrical load. This process may be attributed to the effect of the "electrical cooling" of a PV cell. The knowledge of the p-n junction overheating temperature allows estimation of the heat removal effectiveness in a given module design. In addition, it becomes possible to predict the PV conversion efficiency and operation lifetime of the modules under different environmental conditions.

The present research is aimed at establishing a procedure at which evaluation of the p-n junction overheating temperature in the cells is carried out when connected to an external electric load in maximum power point (MPP) mode. In the procedure, a principle for evaluating the cell temperature using $V_{\mathrm{OC}}$ measurements is applied [10], [11]. The possibility of implementing this principle arises when a fast cell switching from the MPP to the OC mode is performed [12]. Due to the heat capacity of the cell material, the temperature does not change over a short period of time immediately after switching the external load OFF. The $V_{\mathrm{OC}}$ amplitude, measured at this moment, is compared with the corresponding value in a "cold" state of the cell. The latter could be realized just after step-like initiation of illumination. Then, the overheating temperature is calculated using the calibration data of $V_{\mathrm{OC}}=f(T)$ measured under flash illumination.

Generally speaking, one may encounter certain difficulties at arranging the "cold" state of a PV converter. In researching solar modules, attempts of fast mechanical shuttering of the whole module aperture to sun illumination did not provide desirable results. The reason is that at the moment, when the $V_{\mathrm{OC}}$ is measured, the temperature of the cells in different module parts may differ significantly [12], [14]. A similar problem can also arise when researching the laser beam converters of rather large dimensions [1]. Unlike [12], in the present work, temperature control is added by placing a temperature sensor on an external part of the module near one of the PV cells. Corresponding temperature values are used for accurate determination 


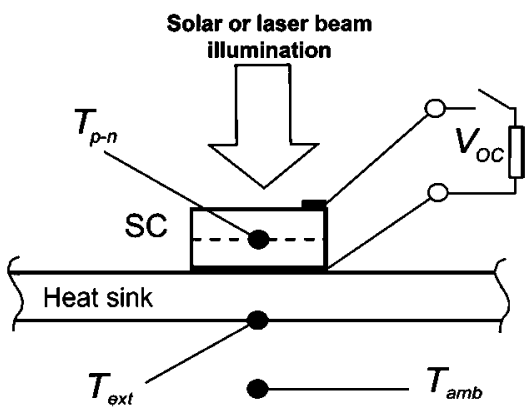

Fig. 1. Scheme for measuring the parameters by the procedure under conditions of continuous illumination of a PV cell.

of the $V_{o c}$ value at the ambient temperature by calculations (this approach has been briefly described in our recent work [14]). A detailed verification of the proposed approach has been provided using single-junction $\mathrm{AlGaAs} / \mathrm{GaAs}$ cells converting laser beam radiation. The temperature dynamics in the PV cells has been determined under flash illumination and during fast commutation of the load. Temperature measurements were taken in two cases: converting continuous laser power by single-junction cells and converting solar power by triple-junction cells operating in the concentrator modules.

\section{Procedure for Measuring P-N Junction OVERHEATING TEMPERATURE}

Fig. 1 shows the scheme of the measuring procedure under conditions of continuous illumination of a PV cell.

The light is directed onto the photoreceiving area of a PV cell mounted on a heat sink. Connecting a load resistance to the cell causes a photocurrent flow through this resistance so that a part of the power absorbed by the PV cell is transferred to the load.

The cell p-n junction temperature $T_{\mathrm{p}-\mathrm{n}}$ depends on the ambient temperature $T_{\mathrm{amb}}$, illumination intensity, and the conditions of the power transfer to the load. It also depends on the conditions of the heat transfer to a heat sink (these conditions determine the temperature of any heated part of the module rear $\left.T_{\text {ext }}\right)$.

The p-n junction overheating temperature $\Delta T_{\mathrm{p}-\mathrm{n}}$ under conditions of thermal balance in any operational mode is the temperature difference:

$$
\Delta T_{\mathrm{p}-\mathrm{n}}=T_{\mathrm{p}-\mathrm{n}}-T_{\mathrm{amb}} .
$$

It is known that at the definite density of the current generated in a PV cell, the $V_{\mathrm{oc}}=f(T)$ dependence is a linear function within a temperature range near the room temperature [10]. For this reason, one can write that

$$
\Delta T_{\mathrm{p}-\mathrm{n}}=\frac{1}{\alpha \times 10^{-3}}\left(V_{\mathrm{OC}}-V_{\mathrm{OC}}^{\mathrm{amb}}\right)
$$

where $\alpha\left[-\mathrm{mV} /{ }^{\circ} \mathrm{C}\right]$ is the temperature coefficient of $V_{\mathrm{OC}}$ at a given current density; and $V_{O C}$ and $V_{O C}^{a m b}$ are the $O C$ voltages at a balanced temperature and the ambient temperature, respectively.

A temperature gradient arises between the cell p-n junction area and the external surface of the module. At moderate over- heating and under thermal balance conditions, one can write

$$
\Delta T_{\mathrm{p}-\mathrm{n}}=B \Delta T_{\mathrm{ext}}=B\left(T_{\mathrm{ext}}-T_{\mathrm{ext}}^{\mathrm{amb}}\right)
$$

where $B$ is a coefficient; and $T_{\text {ext }}^{\mathrm{amb}}$ is the initial heat sink temperature equal to the ambient temperature $T_{\mathrm{amb}}$. For MPP mode, $\Delta T_{\mathrm{p}-\mathrm{n}}^{\mathrm{MPP}}$ value is determined as

$$
\begin{aligned}
& \Delta T_{\mathrm{p}-\mathrm{n}}^{\mathrm{MPP}}=\frac{1}{\alpha \times 10^{-3}}\left(V_{\mathrm{OC}}^{\mathrm{MPP}}-V_{\mathrm{OC}}^{\mathrm{amb}}\right) \\
& =B\left(T_{\mathrm{ext}}^{\mathrm{MPP}}-T_{\mathrm{ext}}^{\mathrm{amb}}\right)
\end{aligned}
$$

where $V_{\mathrm{OC}}^{\mathrm{MPP}}$ is the value measured just after the fast disconnection of the load, and $T_{\mathrm{ext}}^{\mathrm{MPP}}$ is the value corresponding to the thermal balance of the system before the load was disconnected.

To exclude the unknown coefficient $B$ and to find $V_{O C}^{a m b}$, one can set up a similar equation for the conditions of zero power transfer in the OC mode (the p-n junction overheating temperature is denoted as $\Delta T_{\mathrm{p}-\mathrm{n}}^{\mathrm{OC}}$ ):

$$
\Delta T_{\mathrm{p}-\mathrm{n}}^{\mathrm{OC}}=\frac{1}{\alpha \times 10^{-3}}\left(V_{\mathrm{OC}}-V_{\mathrm{OC}}^{\mathrm{amb}}\right)=B\left(T_{\mathrm{ext}}^{\mathrm{OC}}-T_{\mathrm{ext}}^{\mathrm{amb}}\right) .
$$

In (5), $V_{\mathrm{OC}}$ is the $\mathrm{OC}$ voltage of the cell at a given illumination level under thermal balance conditions; $T_{\mathrm{ext}}^{\mathrm{OC}}$ is the temperature, which is measured in the OC mode on the external part of the module. From (4) and (5), one can obtain

$$
V_{O C}^{a m b}=\frac{V_{O C}^{M P P}\left(T_{e x t}^{O C}-T_{a m b}\right)-V_{O C}\left(T_{e x t}^{M P P}-T_{a m b}\right)}{T_{e x t}^{O C}-T_{e x t}^{M P P F}} .
$$

Knowing $V_{O C}^{\mathrm{amb}}$, one can calculate $\Delta T_{\mathrm{p}-\mathrm{M}}^{\mathrm{MPP}}$ from (4) and $\Delta T_{p-n}^{\mathrm{OC}}$ from (5). According to the procedure under consideration, the ambient temperature $T_{\mathrm{amb}}$ is measured as the heat sink temperature $T_{\text {ext }}^{\mathrm{amb}}$ before illumination (see Fig. 1). The tested device is irradiated by a definite source while connected to the optimum load. Under irradiation, after a certain period of time required to reach the thermal balance, the heat sink temperature is recorded. It is denoted as the $T_{\mathrm{ext}}^{\mathrm{MPP}}$ corresponding to the MPP mode of the cell operation. At the next step, the PV cell is quickly switched to the OC mode of operation. The amplitude of the overvoltage is measured with a memory oscilloscope. Since the $\mathrm{p}-\mathrm{n}$ junction still continues to be at the temperature $T_{\mathrm{p}-\mathrm{n}}^{\mathrm{MPP}}$, this voltage is denoted as $V_{\mathrm{OC}}^{\mathrm{MPP}}$. While reaching a new thermal equilibrium in the OC mode, the cell is heated up to higher temperature at the same incident power. The OC voltage and corresponding heat sink temperature $T_{\text {ext }}^{\mathrm{OC}}$ are measured (they are denoted as $V_{O C}$ and $T_{\text {ext }}^{O C}$ ). Fig. 2 shows the time-dependent behavior of the heat sink temperature and voltage drop across the p-n junction of the cell in MPP and OC modes of operation.

For determining $V_{O C}^{\mathrm{amb}}$, the measured voltage values and corresponding temperature values should be substituted into (6). Then, the required value of $\Delta T_{\mathrm{p}-\mathrm{n}}^{\mathrm{MPP}}$ can be found from (4). In the "Temperature-Voltage" coordinates, the $V_{\mathrm{OC}}^{\mathrm{amb}}$ value lies on the continuation (up to $T=T_{\mathrm{amb}}$ ) of the straight line connecting the values of $V_{\mathrm{OC}}$ and $V_{\mathrm{OC}}^{\mathrm{MPP}}$. The corresponding graphical plot is presented in Fig. 3.

\section{INITIAL DATA AND CONDITIONS FOR THE EXPERIMENTS}

The initial data for determining the p-n junction overheating temperature are the $\mathrm{OC}$ voltage temperature coefficients for 


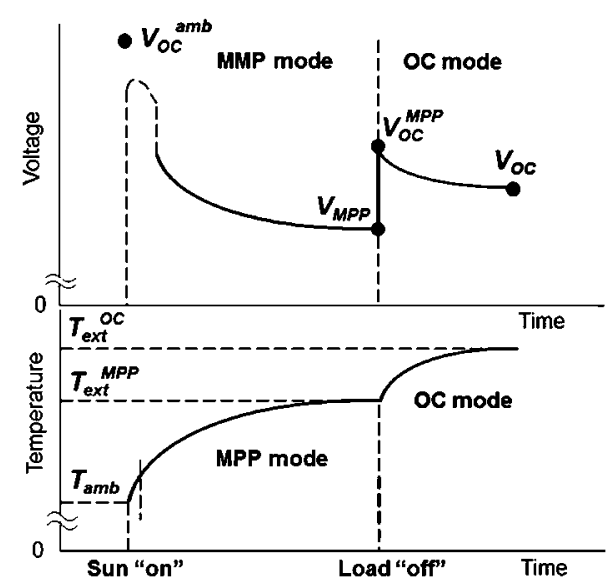

Fig. 2. Time-dependent behavior of the heat sink temperature and of the $\mathbf{p}-\mathrm{n}$ junction voltage for a PV cell in MPP and OC mode.

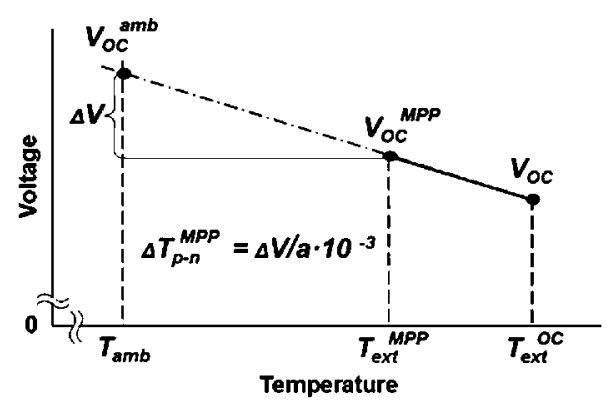

Fig. 3. Dependence of the cell $\mathrm{OC}$ voltage on the temperature on the external module surface. From this graph, the $V_{O C}^{\mathrm{amb}}$ value can be determined [see (6)].

definite PV cells used in the tested PV devices. In this study, these data have been obtained under flash illumination of the cells placed on a temperature-controlled holder. The PV cell operation under continuous illumination was analyzed using a specialized electronic unit ensuring proper regulation and fast disconnection of the external load. The characteristic rates of the p-n junction temperature changes have been evaluated in the time-dependent $V_{O C}$ measurements.

\section{A. Experimental Specimens}

The single-junction AlGaAs/GaAs $4 \mathrm{~mm} \times 4 \mathrm{~mm}$ PV cells [2] soldered onto a $30 \mathrm{~mm} \times 30 \mathrm{~mm} \times 3 \mathrm{~mm}$ copper holder have been used in the indoor experiments on converting the $\lambda=808 \mathrm{~nm}$ laser radiation. For the experiments on converting concentrated sunlight, the triple-junction $\mathrm{GaInP} / \mathrm{GaIn} \mathrm{As} / \mathrm{Ge}$ $2.6 \mathrm{~mm} \times 2.6 \mathrm{~mm}$ cells soldered in groups onto the 1 -mm-thick steel heat sinks have been used [4]. The groups of the cells and silicone-on-glass Fresnel lenses were combined into the solar concentrator modules of SMALFOC design (Small lenses, Multijunction cells, All made from glass, Lamination, Fresnel, Optics, Concentration) [15]. The parallel-series connection of the $288 \mathrm{PV}$ cells ensured the module output voltage of about $36 \mathrm{~V}$.

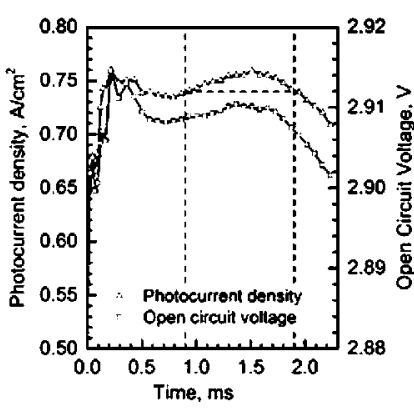

(a)

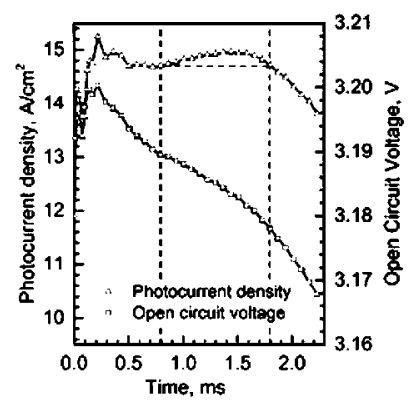

(b)
Fig. 4. Photocurrent densities and corresponding $\mathrm{OC}$ voltages for one of the triple-junction GaInP/GaIn As/Ge PV cells under flash illumination from a sunlight simulator. The illumination intensities correspond to the sun concentration ratios of (a) $60 \times$ and (b) $1215 \times$. The cell specimen was in mechanical contact with a holder at room temperature.

\section{B. Temperature-Dependent $V_{\mathrm{OC}}$ Measurements Under Flash Illumination}

The dependences of $V_{\mathrm{OC}}$ on the temperature for the PV cells were measured using a flash simulator of concentrated sunlight [16]. The AM 1.5 sun concentration ratios varied in the range of $C=1-1000$ and the cell temperatures in the range of -20 to $+100^{\circ} \mathrm{C}$. The illumination intensity was controlled by recording the photocurrent pulses. To register the signals, a specially designed analog-to-digital memory oscilloscope was used. Fig. 4 shows the current and voltage pulse shapes recorded for one of the solar triple-junction cells at the illumination intensities equivalent to the concentration ratios of $60 \times$ and $1215 \times$.

Note that in only one experiment, the tested solar cell was not soldered to a heat-dissipating holder, but was simply in a mechanical contact at room temperature. The comparison of the plots for the $V_{\mathrm{OC}}$ at the lower and the higher illumination intensities in Fig. 4 shows that until $0.5 \mathrm{~ms}$, the heating effect is insignificant. However, after this moment, the heating effect is pronounced at the higher equivalent concentration ratio.

For the triple-junction cells, the photocurrent densities have been generated, which are typical for the further outdoor experiments with concentrator modules. The corresponding data are presented in Fig. 5. As was supposed in Section II in considering the procedure for measuring the $\mathrm{p}-\mathrm{n}$ junction overheating temperature, the $V_{\mathrm{OC}}=f(T)$ dependences are well approximated by the straight lines. The temperature coefficients $\alpha$ for the $O C$ voltage at different photocurrent densities were determined from the slopes of the straight lines connecting the measurement points. The values of these coefficients are presented in Fig. 6 .

\section{Dynamics of the Thermal Characteristics of the Photovoltaic Cells}

The measurements of the $V_{\mathrm{OC}}$ under flash illumination allow the time-dependent p-n junction temperature to be estimated at a fast change of the thermal load. In Fig. 4, the current values are equal at the beginning and the end of the interval from 1 to $2 \mathrm{~ms}$. Thus, one can measure two $V_{\mathrm{OC}}$ values within the 1-ms interval, when the cell is absorbing a certain amount of light power, so that its temperature increases. Using the plots 


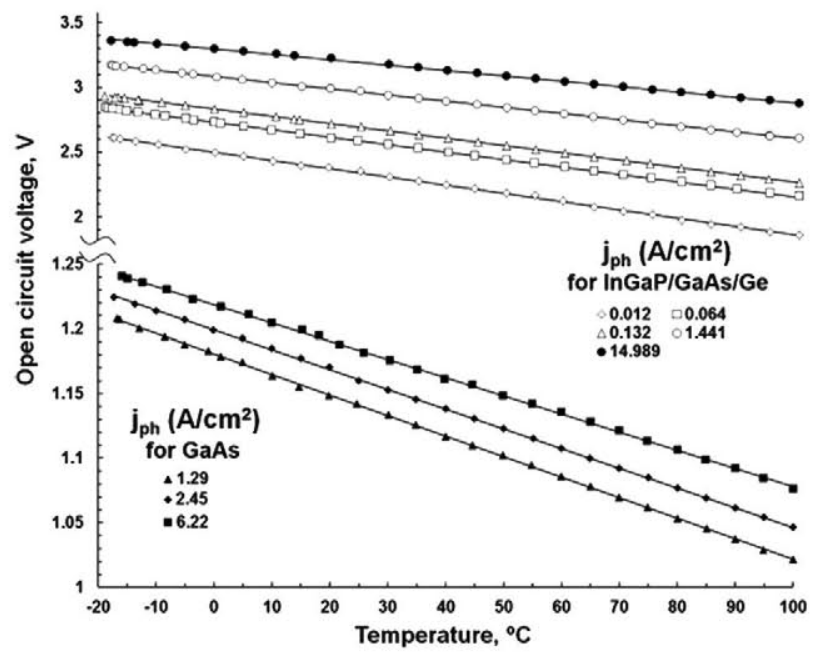

Fig. 5. $V_{O C}$ values for specimens of the single-junction and triple-junction PV cells at the different temperatures and photocurrent densities obtained under flash illumination.

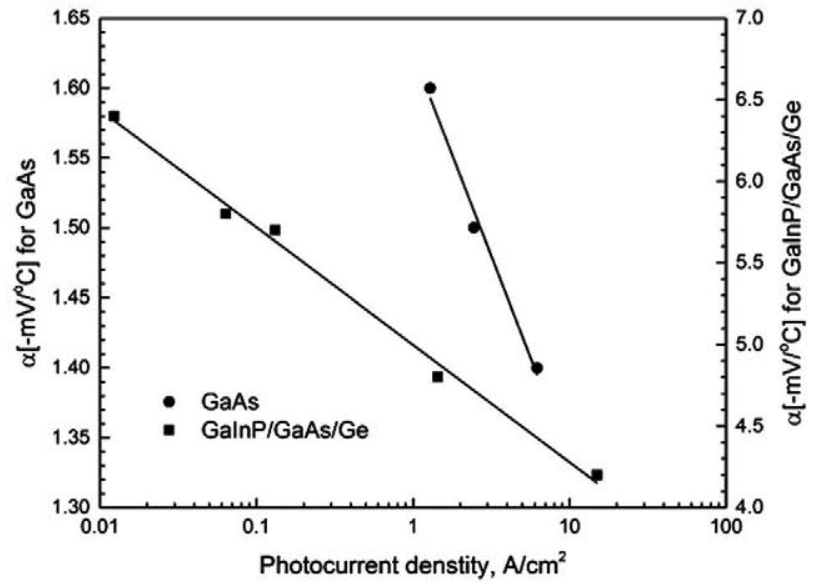

Fig. 6. Temperature coefficients $\alpha$ for specimens of the single-junction and triple-junction PV cells obtained from the plots of Fig. 5 at different photocurrent densities.

in Figs. 5 and 6, one can estimate the rise in the p-n junction temperature depending on the illumination intensity at different conditions of heat removal. Fig. 7 shows the p-n junction overheating temperature versus the generated photocurrent density measured for a triple-junction PV cell. The experimental data have been obtained for the specimens mechanically pressed or soldered onto a holder.

Fig. 7 shows that the p-n junction temperature of the soldered specimen increases by about $1^{\circ} \mathrm{C}$ during $1 \mathrm{~ms}$ at the illumination intensity equivalent to the sun concentration ratio of $C=1000 \times\left(14 \mathrm{~A} / \mathrm{cm}^{2}\right)$. This result is in good agreement with data of a recent work [17]. At a pressure contact of the specimen with a holder, the overheating temperature is three times greater. Similar result has been obtained by theoretical estimation of the temperature increase in a thermally isolated cell made of Ge as the main cell material. In the latter case, the Ge heat capacity and the amount of heat power absorbed during $1 \mathrm{~ms}$ were taken into

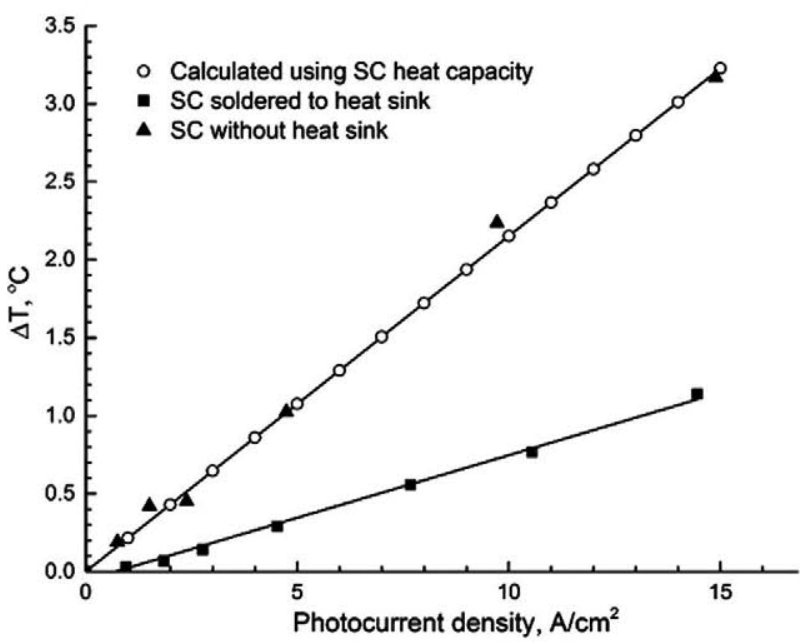

Fig. 7. Rise in the p-n junction temperature, depending on the photocurrent density for the triple-junction PV cells at the end of the light pulse that is $1 \mathrm{~ms}$ in duration. The following conditions for heat removal have been considered: specimen in pressure contact with a holder (the triangular points) and a soldered specimen (square points). The round points denote the calculated temperature rise in a cell chip made of $\mathrm{Ge}$ as the main material.

account, which means that without soldering, the heat transfer from a PV cell to the holder is rather weak.

The results presented in Fig. 7 can be used for estimating the heating dynamics in the single-junction PV cells converting laser radiation. For instance, at a sunlight thermal power density of approximately $100 \mathrm{~W} / \mathrm{cm}^{2}(C=1000 \times)$, in a solar triple-junction cell, the photocurrent density is about $15 \mathrm{~A} / \mathrm{cm}^{2}$. As regards, a single-junction 50\%-efficient $\mathrm{AlGaAs} / \mathrm{GaAs}$ cell, converting similar amount of incident power, the photocurrent density should be about $50 \mathrm{~A} / \mathrm{cm}^{2}$ at an output voltage of about $1 \mathrm{~V}$. Therefore, the overheating temperature estimation using the graphs in Fig. 7 will always give a conservative value.

\section{Measurement Equipment}

A computerized analog-to-digital device has been used in the experiments on evaluating the overheating temperature of the p-n junctions in the PV cells for the conversion of laser and solar radiation. The setup, which is shown in Fig. 8(a), ensured the recording of the voltage and current magnitudes by varying the PV cell mode of operation. A controllable FET was used as a load resistance. This resistance could be automatically varied for providing the maximum of extracting power, as well as the fast load disconnection for the OC mode arrangement. The PT100 thermoresistors were used for the temperature measurements. In the outdoor tests under the sun illumination, the SMALFOC concentrator modules mounted on a sun tracker were used. The mechanical equipment for this experiment is pictured in Fig. 8(b).

\section{EXPERIMENTAL RESULTS}

The individual single-junction $\mathrm{AlGaAs} / \mathrm{GaAs} \mathrm{PV}$ cells were tested under laser beam illumination with an aperture of about $1 \mathrm{~mm}$. A rather fast mechanical shutter $(\sim 0.2 \mathrm{~ms})$ was used for switching on the specimen illumination. The cell $\mathrm{OC}$ voltage 


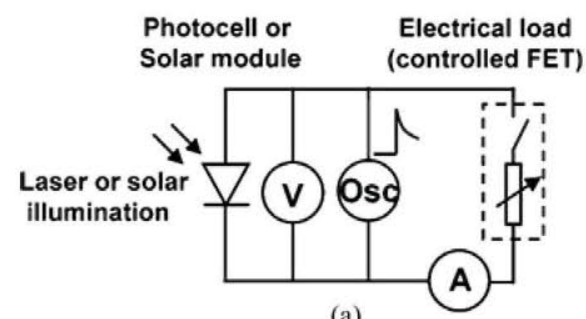

(a)

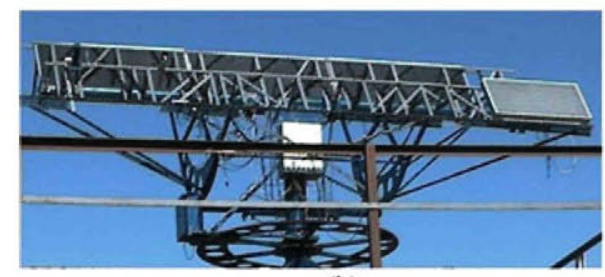

(b)

Fig. 8. (a) Simplified circuit for the recording of the voltage and current magnitudes when varying the PV cell mode of operation. (b) Sun-tracker with the $0.5 \mathrm{~m} \times 1.0 \mathrm{~m}$ concentrator module of the SMALFOC design [15].

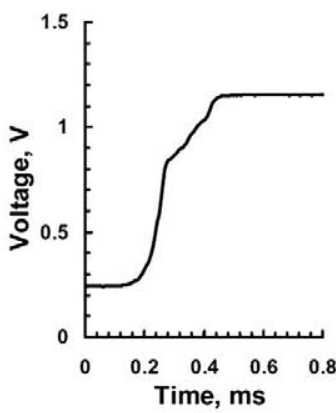

(a)

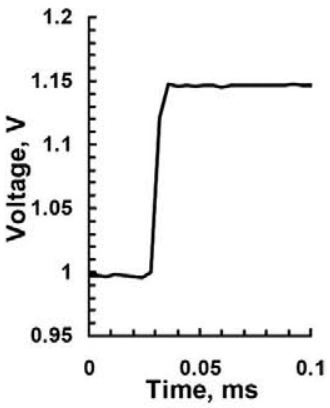

(b)
Fig. 9. (a) Oscillogram of the OC voltage in AlGaAs/GaAs PV cell in opening a mechanical shutter. (b) Oscillogram of changeover from the MPP regime to the $\mathrm{OC}$ one realized at FET operation.

oscillogram in the shutter opening is shown in Fig. 9(a). In the experiments with laser illumination, it was possible to measure directly the $V_{\mathrm{OC}}^{\mathrm{amb}}$ value to compare it with that determined from the procedure in Section II. Therefore, the results of this part of the experiment may be used for verification of the calculations performed with (4) and (5).

The time-dependent characteristic of the cell switching from the MPP to the OC mode is shown in Fig. 9(b). It is seen that the FET activation time is about $0.01 \mathrm{~ms}$ so that the correct measurement of the $V_{O C}^{\mathrm{MPP}}$ magnitude is ensured. The rather fast cell illumination switching on [0.2 ms, Fig. 9(a)] and very fast switching of the external load [see Fig. 9(b)] may cause an evaluation uncertainty of $\Delta T_{\mathrm{p}-\mathrm{n}}^{\mathrm{MPP}}$ value of about $0.2^{\circ} \mathrm{C}$. It was mentioned above that such a direct $V_{\mathrm{OC}}^{\mathrm{amb}}$ measurement cannot be carried out outdoors when working on large-area solar modules.

The experimental conditions are listed in Table I. In addition, the results of the temperature and $\mathrm{OC}$ voltage measurements and calculations are shown. Left and right columns contain data on conversion of the laser power and solar power, respectively. The ambient temperature $T_{\text {amb }}$ was recorded with accuracy up
TABLE I

EXPERIMENTAL CONDITIONS AND THE RESUlTS OF THE TEMPERATURE AND OC Voltage MEASUREMENTS and CALCULATIONS IN THE PV CONVERSION OF LASER AND SOLAR RADIATIONS

\begin{tabular}{|c|c|c|}
\hline Parameters & $\begin{array}{c}\text { Laser beam } \\
\text { illumination } \lambda=808 \\
\mathrm{~nm}, \mathrm{P}=0.71 \mathrm{~W} \\
\mathrm{AlGaAs} / \mathrm{GaAs} \mathrm{PV} \text { cell } \\
4 \mathrm{~mm} \times 4 \mathrm{~mm} \\
\text { soldered to a copper } \\
\text { holder } \\
30 \times 30 \times 3 \mathrm{~m} \mathrm{~m}^{3} \text { in } \\
\text { size; } \\
\alpha=-1.51 \mathrm{~m} \mathrm{~V} /{ }^{\circ} \mathrm{C} \\
\text { at } \\
j_{\mathrm{ph}}=2.71 \mathrm{~A} / \mathrm{cm}^{2}\end{array}$ & $\begin{array}{c}\text { Sun illumination } \\
865 \mathrm{~W} / \mathrm{m}^{2} \text {, Wind speed } \\
2 \mathrm{~m} / \mathrm{s} ; \text { SMALFOC } \\
\text { module of } \\
0.5 \mathrm{~m} \times 1 \mathrm{~m} \text { in area } \\
\text { with } 288 \text { pairs of lenses } \\
\text { and GaInP/GaInAs/Ge } \\
\text { cells; } \\
\alpha=-4.68 \mathrm{~m} \mathrm{~V} /{ }^{\circ} \mathrm{C} \\
\text { at } \\
j_{\mathrm{ph}}=2.74 \mathrm{~A} / \mathrm{cm}^{2}\end{array}$ \\
\hline$T_{\mathrm{amb}}$ & 23.0 & 15.7 \\
\hline$T_{\mathrm{ext}}^{\mathrm{amb}}$ & 23.02 & 17.91 \\
\hline$T_{\mathrm{ext}}^{\mathrm{MPP}}$ & 36.78 & 28.19 \\
\hline $\begin{array}{l}T_{\text {ext }}^{0} \mathrm{C} \\
0\end{array}$ & 45.58 & 31.88 \\
\hline$V_{O O}^{M P P}$ & 1.12979 & 35.80 \\
\hline$V_{0} \mathrm{C}$ & 1.11526 & 35.31 \\
\hline$V_{O \mathrm{C}}^{\mathrm{amb}}$ (calculated) & 1.15251 & 37.46 \\
\hline$V_{O \mathrm{C}}^{\mathrm{am}}$ (measured) & 1.15265 & \\
\hline$\Delta T_{\mathrm{p}-\mathrm{M}}^{\mathrm{MPP}}($ calculated $)$ & 15.1 & 29.4 \\
\hline$\Delta T_{\mathrm{p}-\mathrm{n}}^{\mathrm{OC}}$ (calculated) & 24.7 & 38.1 \\
\hline
\end{tabular}

The temperature values $T$ are in degrees centigrade; voltage values $V$ are in volts.

to the first decimal place and the other temperatures up to the second decimal place. The voltage values for the single-junction $\mathrm{AlGaAs} / \mathrm{GaAs}$ PV cell were measured with a maximal possible accuracy. It was necessary for estimation of a probable error in finding the $V_{\mathrm{OC}}^{\mathrm{amb}}$ from a direct measurement and from the calculation by (6). The $\Delta T_{\mathrm{p}-\mathrm{n}}^{\mathrm{OC}}$ and $\Delta T_{\mathrm{p}-\mathrm{n}}^{\mathrm{MPP}}$ values have been calculated using (4) and (5), respectively.

A good fit of the rated $V_{\mathrm{OC}}^{\mathrm{amb}}$ value to the directly measured one in the experiments on converting laser radiation is noteworthy. The $0.14 \mathrm{mV}$ difference corresponds to a temperature error as little as $0.1{ }^{\circ} \mathrm{C}$ in determining the p-n junction overheating temperature. It seems that a similar temperature evaluation error can be typical for the larger-in-size modules in converting laser and solar radiations. Certainly, this does not extend to the cases of the probable nonuniformities for both incoming power and heat removal processes in these modules.

Another source of the errors is a possible uncertainty in choosing coefficient $\alpha$ at the transformation of the voltage values into the temperature ones (see Fig. 6). This coefficient should correspond to the photocurrent density in the cells of a tested photoconversion device. A positive factor is that, at error in determining the photocurrent density in two times, the error of $\alpha$ value is only about $6 \%$.

Let us consider the data of Table I on the temperature in the p-n junction area of the PV cells in the solar concentrator module. The corresponding values for the MPP mode $\Delta T_{\mathrm{p}-\mathrm{n}}^{\mathrm{MPP}}$ and for the $O C$ mode $\Delta T_{\mathrm{p}-\mathrm{n}}^{\mathrm{OC}}$ differ almost 1.3 times. In the MPP mode, the cell temperature is low owing to the "electrical cooling" process (transferring a substantial part of the absorbed power into the external load). The rather low overheating temperature of the p-n junction area $\Delta T_{\mathrm{p}-\mathrm{n}}^{\mathrm{MP}}=29-30{ }^{\circ} \mathrm{C}$ in the high-concentration SMALFOC modules is an indicator of 
a good residual heat dissipation design. For instance, in $\mathrm{OC}$ conditions (see Table I, right column), this temperature is lower in comparison with that measured in [9]. The short path from the cells to air and a high heat radiation efficiency of the lamination cover ensure intensive heat removal in the SMALFOC modules.

\section{Conclusion}

A simple procedure for making $V_{\mathrm{OC}}$ an indicator of operational temperature in MPP mode of the PV cells and modules has been proposed. The $\mathrm{p}-\mathrm{n}$ junction overheating temperature evaluation includes measuring two $\mathrm{OC}$ voltage values and three temperature values. The distinguishing feature of the proposed approach is that one of the $V_{\mathrm{OC}}$ measurements is carried out immediately after the fast disconnection of the external resistive load. The indoor verification of the method for a PV converter of laser radiation has shown quite a small error in the temperature evaluation (about $0.1^{\circ} \mathrm{C}$ ). This error is associated with uncertainty in determining the $\mathrm{OC}$ voltage temperature coefficient. The corresponding coefficient is obtained from the experiments under flash illumination.

\section{REFERENCES}

[1] M. Smith, B. Tillotson, J. Oliver, and N. Tarasenko, "Development of a laser power beaming experiment," in Proc. 38th IEEE Photovoltaic Spec. Conf., 2012, pp. 2825-2830.

[2] T. Nikitina et al., "PV cells and modules specialized for space wireless energy transfer: Modeling and development," in Proc. 28th Eur. Photovoltaic Sol. Energy Conf. Exhib., 2013, pp. 544-545.

[3] V. M. Andreev, V. A. Grilykhes, and V. D. Rumyantsev, Photovoltaic Conversion of Concentrated Sunlight. Chichester, U.K.: Wiley, 1997, p. 294.

[4] Z. I. Alferov, V. M. Andreev, and V. D. Rumyantsev, "III-V heterostructures in photovoltaics," in Concentrator Photovoltaics. Berlin, Germany: Springer-Verlag, 2007, pp. 25-50.

[5] E. Oliva, F. Dimroth, and A. W. Bett, "GaAs converters for high power densities of laser illumination," Prog. Photovoltaics, Res. Appl., vol. 16, no. 4, pp. 289-295, 2008.

[6] D. J. Friedman, R. R. King, R. M. Swanson, J. McJannet, and D. Gwinner, "Editorial: Toward 100 Gigawatts of concentrator photovoltaics by 2030 ," IEEE J. Photovoltaics, vol. 3, no. 4, pp. 1460-1463, Oct. 2013.

[7] E. Wesoff. (2013, Jun.). Sharp Hits Record 44.4\% Efficiency for TripleJunction Solar Cell. [Online]. Available: http://www.greentechmedia.com/ articles/read/Sharp-Hits-Record-44.4-Efficiency-For-Triple-JunctionSolar-Cell

[8] A. Luque, "Will we exceed 50\% efficiency in photovoltaics?" J. Appl. Phys., vol. 110, no. 3, pp. 1-19, 2011.

[9] M. Wiesenfarth, S. Gamisch, H. Kraus, and A. W. Bett, "Investigations on 3-dimensional temperature distribution in a FLATCON-type CPV module," in Proc. AIP Conf., 2013, 1556, p. 189.

[10] G. S. Kinsey et al., "Concentrator multijunction solar cell characteristics under variable intensity and temperature," Prog. Photovoltaics, Res. Appl., vol. 16, pp. 503-508, 2008.

[11] W. Bagienski, G. S. Kinsey, M. Liu, A. Nayak, and V. Garboushian, "Open circuit voltage temperature coefficients versus concentration: Theory, indoor measurements, and outdoor measurements," in Proc. AIP Conf., 2012, vol. 1477, p. 148.

[12] V. D. Rumyantsev et al., "Cell chip temperature measurements in different operation regimes of HCPV modules," in Proc. AIP Conf., 2013, vol. 1556, p. 138.

[13] M. Muller, C. Deline, B. Marion, S. Kurtz, and N. Bosco, "Determining outdoor CPV cell temperature," in Proc. AIP Conf., 2011, vol. 1407, pp. 331-335.

[14] V. D. Rumyantsev et al., "Temperature of solar cells with regard to photoactive and non-photoactive light absorption in concentrator PV modules," in Proc. AIP Conf., 2014, vol. 1616, pp. 154-157.

[15] V. D. Rumyantsev et al., "Progress in developing HCPV modules of SMALFOC-design," in Proc. AIP Conf., 2013, vol. 1556, p. 185.
[16] V. D. Rumyantsev et al., "Evaluation of the solar cell internal resistance in I-V measurements under flash illumination," in Proc. AIP Conf., 2012, vol. 1477 , pp. $152-156$.

[17] A. Braun, B. Hirsch, A. Vossier, E. Katz, and J. Gordon, "Temperature dynamics of multijunction concentrator solar cells up to ultra-high irradiance," Prog. Photovoltaics, Res. Appl., vol. 21, pp. 202-208, 2013.

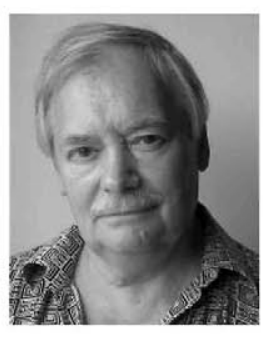

Valery D. Rumyantsev was born in Leningrad, USSR, in 1946. In 1970, he graduated with distinction from the Saint Petersburg University of Information Technologies, Mechanics and Optics, Saint Petersburg, Russia, with specialization in quantum electronics and optoelectronic devices. He received the Ph.D. degree and the Doctor of Science degree in physics and mathematics both from the Ioffe Physical Technical Institute, Saint Petersburg, in 1978 and 1989 , respectively.

He obtained the title of Professor for his work in supervising postgraduate students' Ph.D. activities. From 1974 to 1986, he was a Research Engineer with the PV Lab of the Ioffe Physical Technical Institute; from 1986 to 1991, he was a Senior Scientist with the same institute; since 1991, he has been a Principal Scientist, also with the same institute. He is the author of more than 250 published works in scientific journals and conference proceedings, including two monographs and three chapters in books concerning the theory and practice of the CPV approach. Numerous patents on technical solutions are also under his name. His research interests include terrestrial concentrator PV installation, flash solar simulators, solar tracking systems, design of concentrator PV modules, thermovoltaic converters, liquid phase epitaxy, converters of laser radiation, and PV cell characterization.

Prof. Rumyantsev's awards and honors include the USSR National Prize for young scientists (Komsomol Prize) for a series of works on "Semiconductor sources of visible light" in 1976, an honorary insignia "Inventor of the USSR" in 1982, a silver medal at the USSR National Exhibition of advanced achievements in 1984, and the "A.F. Ioffe Prize on Semiconductor Physics" from the Russian Academy of Sciences for a series of works on "Photovoltaic converters of concentrated sunlight" in 1996.

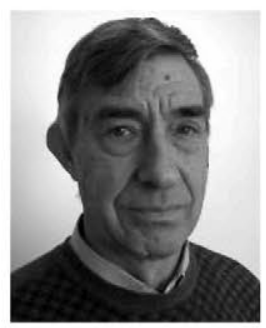

Nikolay Yu Davidyuk was born in Zlatoust, USSR, in 1946. He received the specialist degree in quantum electronics and optoelectronic devices from the Institute for Precision Mechanics and Optics, Saint Petersburg, Russia, in 1970 and the Ph.D. degree in physics and mathematics from the Ioffe Physical Technical Institute, Saint Petersburg, in 1978.

From 1974 to 1986, he was a Research Engineer with the Laboratory of Semiconductor Luminescence and Injection Light Sources, Ioffe Physical Technical Institute; from 1987 to 1991, he was Head of the $\mathrm{Di}$ vision of the Design Office of Ioffe Institute; since 2006, he has been a Principal Engineer with the PV Lab of the same institute. He is the author of more than 60 published works in scientific journals and conference proceedings. His research interests include methods of temperature measurements in PV cells, the design of terrestrial concentrator PV installations, concentrator modules with secondary lenses, and converters of laser radiation.

Dr. Davidyuk received honorary insignia "Inventor of the USSR" in 1982.

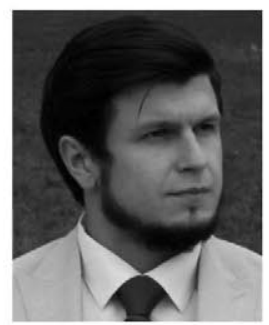

Alexander V. Chekalin was born in Leningrad, USSR, in 1988. He received the Specialist degree in nanoelectronic engineering from the Baltic State Technical University "VOENMEH," Saint Petersburg, Russia, in 2011. He is currently working toward the Ph.D. degree in condensed matter physics with the Ioffe Physical Technical Institute, Saint Petersburg.

From 2010 to 2011, he was an Assistant with the Photovoltaic Converters Laboratory, Ioffe Physical Technical Institute, where he has been a Senior Assistant since 2011. His research interests include development and manufacturing terrestrial concentration PV installations, development of solar simulator devices, and characterization of PV cells and modules. 


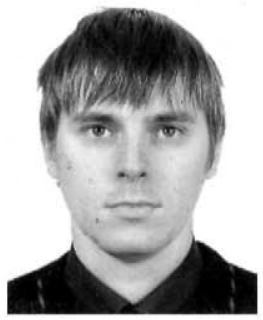

Dmitry A. Malevskiy was born in Leningrad, USSR, in 1981. He received the B.S. and M.S. degrees in solid-state physics and optics from the Saint Petersburg State Polytechnic University, Saint Petersburg, Russia, in 2011.

From 2003 to 2012, he was an Engineer with Technoexan Ltd., Saint Petersburg. Since 2009, he has been a Scientist with the Ioffe Physical Technical Institute, Saint Petersburg. He is a coauthor of more than 15 scientific publications. His research interests include characterization methods and measurement equipment for concentrator solar cell and modules, monitoring systems for photovoltaic modules, digital electronics development, and programming in Java, $\mathrm{C}++, \mathrm{C}$, HTML, and LabView.

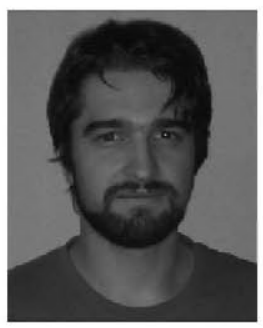

Alexander N. Pan'chak was born in Leningrad, USSR, in 1990. He received the B.S. and M.S. degrees in semiconductor optoelectronics engineering from the Saint Petersburg Electrotechnical University "LETI," Saint Petersburg, Russia, in 2013. He is currently working toward the $\mathrm{Ph} . \mathrm{D}$. degree in condensed matter physics with the Ioffe Physical Technical Institute, Saint Petersburg.

From 2010 to 2013, he was an Assistant with the Photovoltaic Converters Laboratory, Ioffe Physical Technical Institute, where he is currently a Senior Assistant. His research interests include development of equipment for testing of photovoltaic (PV) converters, indoor and outdoor PV cell measurements, and software development for cell and module characterization.

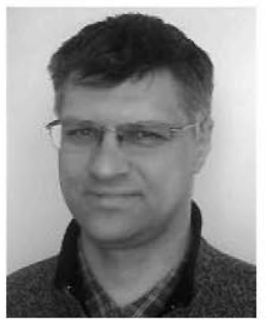

Nikolay A. Sadchikov was born Leningrad, USSR, in 1973. He graduated with honors from the Saint Petersburg University of Information Technologies, Mechanics and Optics, Saint Petersburg, Russia, with specialization in optoelectronic devices and systems in 1997. He received the Ph.D. degree in physics and mathematics from the Ioffe Physical Technical Institute, Saint Petersburg, in 2002.

Since 2001, he has been a Scientific Researcher with the Ioffe Physical Technical Institute. He is a coauthor of more than 35 scientific publications. His scientific interests include the development of optical concentrators based on composite Fresnel lenses, investigation of concentrator photovoltaic (PV) modules with Fresnel lenses and III-V multijunction solar cells, and methods of characterization PV modules with concentrators of sunlight.

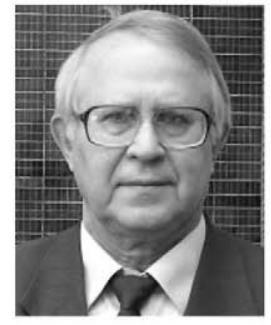

Viacheslav M. Andreev was born in Astrakhan, USSR, in 1941. In 1963, he graduated from the Electrotechnical University, Saint Petersburg, Russia, with specialization in semiconductors. He received the Ph.D. degree in semiconductor devices based on heterostructures and the Doctor's degree in semiconductor lasers, light-emitting diodes (LEDs), and solar cells from the Ioffe Physical Technical Institute, Saint Petersburg, in 1969 and 1980, respectively.

From 1969 to 1981, he was a Researcher with the Ioffe Physical Technical Institute, where he has been the Head of Photovoltaics Laboratory of the Ioffe Physical Technical Institute since 1981. He is the author of 360 publications, including 95 patents and four monographs. His research interests include III-V semiconductor heterostructures and solar photovoltaics, heterolasers, powerful LEDs, radiation detectors, and solar cells for space and terrestrial applications.

Dr. Andreev received the National "Lenin Prize" for the R\&D of heterostructure devices in 1972, the National "State Prize" for R\&D of optoelectronic devices in 1986, the "A.F. Ioffe Prize for Semiconductor Physics" from the Russian Academy of Sciences in 1996, the "European Becquerel Prize" for R\&D in the field of photovoltaics in 2001, the Humboldt Research Award in 2008, the RF President's award entitled "Honored Worker of Science of the Russian Federation" in 2009, and the Karl W. Boer Solar Energy Medal of Merit Award in 2013 .

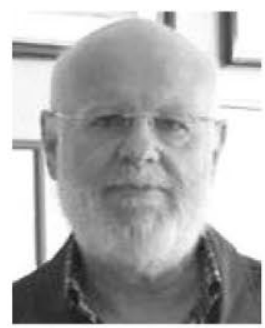

Antonio L. Luque was born in Malaga, Spain, in 1941. He received the M.S. degree in telecommunication engineering from the Escuela Técnica Superior de Ingenieros de Telecomunicación, Madrid, Spain, in 1964 and the M.S. degree in solid-state physics from the University of Toulouse, Toulouse, France, in 1965 .

He was a Founder and Director of the Solar Energy Institute, Polytechnic University of Madrid (UPM) from 1979 to 1985 and from 1986 to 2009 . From 1970 to 2012, he was a Chair Professor of electronics with the School of Telecom, UPM. He is currently an Emeritus Chair Professor with UPM. From 1981 to 1990 , he was a Founder and Chairman of the Board of Directors of Isofoton SL. Since 2013, he has been the Head of Nanostructured Solar Cells Laboratory, Ioffe Physical Technical Institute, Saint Petersburg, Russia. He is the author of more than 400 publications, 22 patents, and 21 book chapters. He is an editor of five books. His research interests include low-cost solar silicon, concentrator photovoltaics, third-generation solar cells, polysilicon, multijunction solar cells, and cells with intermediate bandgap.

Prof. Luque received the National Prize for Technology Research "Leonardo Torres Quevedo" in 1987, the "Alexandre-Edmond Becquerel Prize" in 1992, the National Prize for Technology Transfer "Juan de la Cierva" in 2003, and the William Cherry Award for Photovoltaic Science and Technology in 2006. $\mathrm{He}$ is a Member of the Scientific Advisory Council, Centre for Advanced Solar Photophysics (Joint Action of NREL+LANL). From 2007 to 2010, he was a Member of the Scientific Council of LITEN/CEA (Grenoble), and from 2005 to 2008, he was a Scientific Advisory Board Member of the Institut für Solarenergieforschung Hamelin, Germany. 